\title{
CONCERNING CHLOROPERLA (PERLIDÆ)
}

\author{
BY NATHAN BANKS \\ Museum of Comparative Zoology.
}

Recently there has been discussion by Frison and Ricker, the latter quoting Claassen, as to whether this name should replace Alloperla. When I made the Classification of the Perlidae in 1906, I had no European collection, and there was then no literature on the European forms of prime value. So I accepted Hagen's use of Isopteryx based on the lack of a folded anal area to the hind wing which is true for our form that he identified as cydippe Newm. I showed that the genus Chloroperla should replace Isopteryx. Since then I have not treated this group, but others have. Enderlein in 1909 applied my classification to the European and exotic forms known to him. Seeing that some of the European species had a small anal area, he wisely used another and more definite character, the fact that the second anal vein of the fore wings is unbranched in all the species, except $I$. serricornis, for which he made a new genus, Isoptena.

In 1912 Okamoto in his revision of the Japanese Plecoptera also uses this unforked second anal as the character of Chloroperla. In $1936 \mathrm{Kimmins}$ reviewed the facts concerning Chloroperla and Isopteryx and agreed with me that the latter is a synonym of the former. He lists three species of Chloroperla in the British fauna, torrentium, tripunctata, and apicalis. The first two have a small anal area to hind wings, the third lacks it. So Kimmins evidently is using the unforked second anal as the generic character. But Needham, Claassen, Frison, and Ricker seem unaware that the unforked second anal has ever been used as the generic character, although they list Enderlein's paper in their bibliographies. Moreover, Needham and Claassen in their description of Chloroperla state that the second anal is branched, and put it under this heading in their synoptic table; however, their figure on Plate 14 shows the second 
anal unbranched. It was doubtless this mistake that led Ricker to describe his Hastaperla. Using the unbranched second anal vein as the generic character, our species (brevis) belongs to Chloroperla as truly as apicalis and tripunctata.

In 1912 when I saw the type of C. cydippe Newm. I noted it had a small anal area with one longitudinal vein; recently Ricker has seen it and says the second anal is forked, so this species is doubtless an Alloperla.

Kimmins considers that the genotype of Chloroperla (lutea Latr. is a synonym of tripunctata. I cannot agree. Latreille says of lutea, "extrémité des antennes noires"; and Newman says of apicalis, "extreme portions of the antennæ intensely black". Neither mention any black border to the pronotum.

Scopoli does not mention antennæ in his description of tripunctata, which, he says, agrees except in some points with grammatica. Of grammatica he says, "antennæ basi flavæ, extrorsum fuscæ". Klapalek in Süsswasserfauna Deutschlands (1909) says for tripunctata that the basal third of the antennæ is yellow, rest black, and that the pronotum is bordered with a black line.

In specimens here (Hagen coll.) tripunctata has mostly brown to black antennæ except basal third or less, while in apicalis (even specimens at least 90 years old) there is a greater part yellow and beyond "intensely black". Since lutea agrees with apicalis in both antennæ and pronotum and in neither with tripunctata, it is evident that lutea Latr. will replace apicalis. In either case brevis belongs to Chloroperla, and Chloroperla is distinct from Alloperla. 

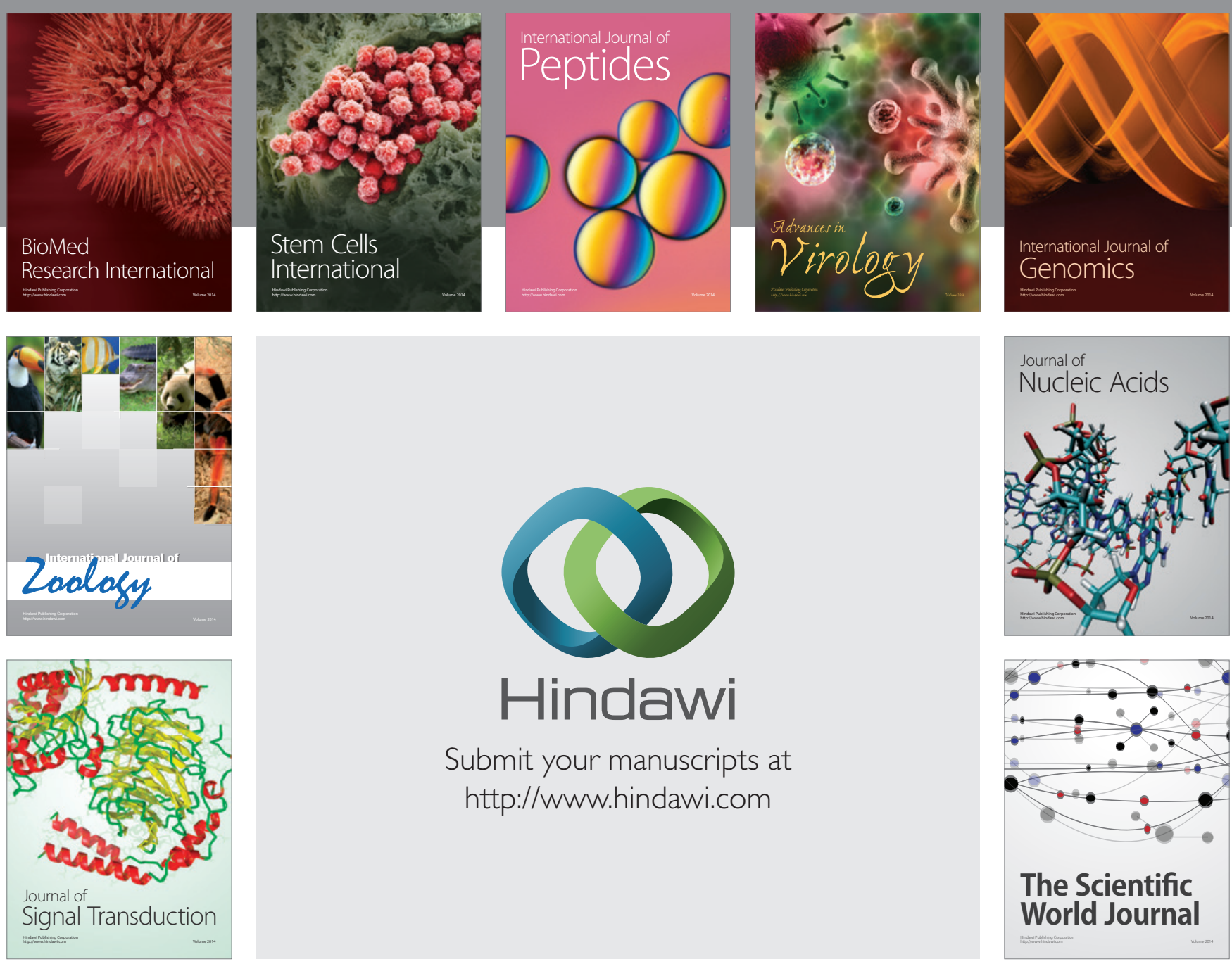

Submit your manuscripts at

http://www.hindawi.com
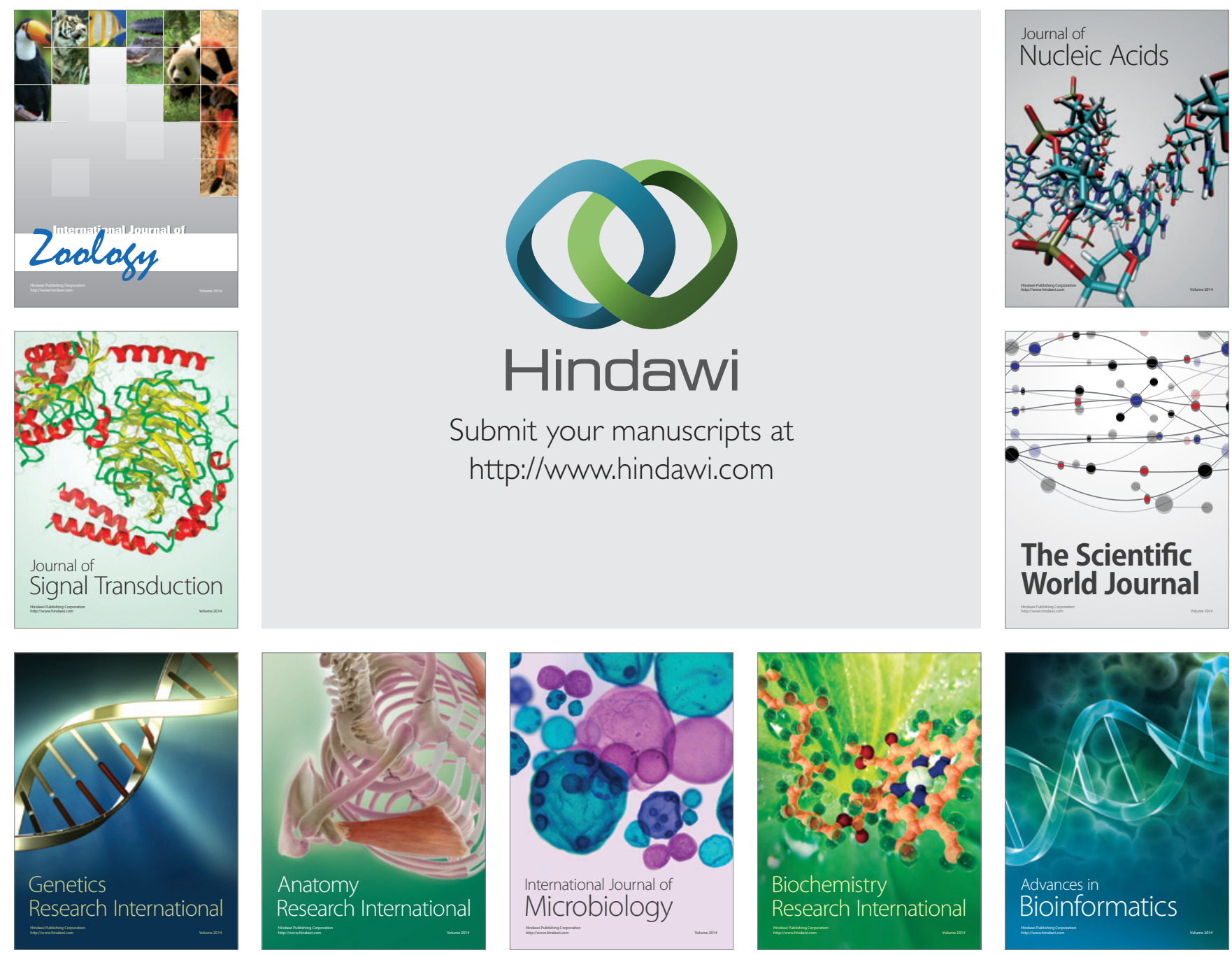

The Scientific World Journal
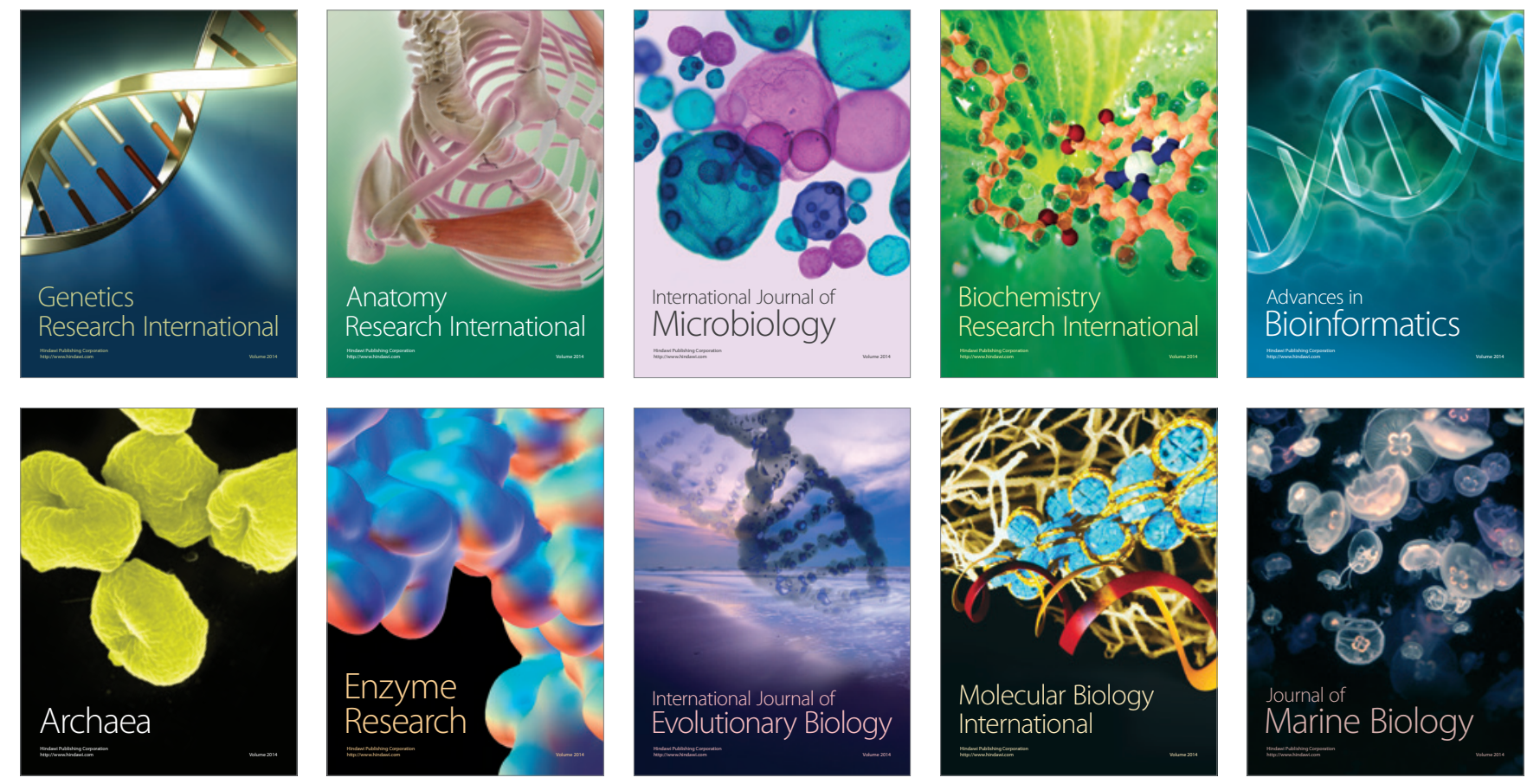